\title{
Falls in Synucleinopathies
}

\author{
Stephen Joza, Richard Camicioli, Fang Ba
}

\begin{abstract}
Parkinson's disease (PD) and other synucleinopathies, namely dementia with Lewy bodies (DLB) and multiple system atrophy (MSA), are common degenerative neurological disorders that share synuclein pathology. Although certain cardinal features of parkinsonism, including bradykinesia and rigidity, respond well to levodopa, axial features, such as gait and balance impairment, are less reliably responsive to dopaminergic therapy and surgical interventions. Consequently, falls are common in PD and other synucleinopathies and are a major contributor toward injury and loss of independence. This underscores the need for appropriate fall risk assessment and implementation of preventative measures in all patients with parkinsonism. The aim of this review is therefore to explore modifiable and non-modifiable risk factors for falls in synucleinopathies. We next review and evaluate the evidence for pharmacological, nonpharmacological, and surgical approaches for fall prevention, and emphasize individualized and multifaceted approaches.
\end{abstract}

RÉSUMÉ: Les risques de chute dans le cas des synucléinopathies. La maladie de Parkinson (MP), de même que d'autres synucléinopathies comme la démence à corps de Lewy (DCL) et l'atrophie multi-systématisée (AMS), sont des troubles neurologiques dégénératifs courants qui ont en commun l'accumulation anormale de protéine synucléine. Bien que certains des principaux symptômes caractéristiques de la MP, par exemple la bradykinésie et la rigidité, répondent bien à la lévodopa, d'autres signes axiaux, par exemple une altération de l'équilibre et de la démarche, vont répondre de façon moins efficace à un traitement dopaminergique et à des interventions chirurgicales. Il s'ensuit que les chutes de patients atteints de la MP et d'autres synucléinopathies contribuent grandement à leur perte d'autonomie, et ce, en raison de blessures. Cette situation met en évidence la nécessité de procéder à une évaluation appropriée des risques de chute chez ces patients et de mettre en œuvre des mesures préventives destinées à tous les patients souffrant de parkinsonisme. L'objectif de cette étude consiste donc, dans le cas des synucléinopathies, à examiner les facteurs de risque modifiables et non-modifiables liés aux chutes. Nous passerons ainsi en revue et évaluerons les approches pharmacologiques, non-pharmacologiques et chirurgicales dans la prévention des chutes pour ensuite mettre en relief des approches individuelles et multidimensionnelles.

Keywords: Parkinson's disease, Dementia with Lewy bodies, Multiple system atrophy, Falls, Risk, Prevention, Management doi:10.1017/cjn.2019.287

Can J Neurol Sci. 2020; 47: 30-43

\section{INTRODUCTION}

Parkinson's disease (PD), dementia with Lewy bodies (DLB), and multiple system atrophy (MSA) are common pathologically overlapping neurodegenerative disorders associated with $\alpha$-synuclein aggregates at autopsy. Parkinsonism is defined as bradykinesia in combination with rest tremor, rigidity, or both. These features must be clearly demonstrable and not attributable to confounding factors. ${ }^{1}$ DLB is defined as dementia (cognitive dysfunction affecting activities of daily living), concurrent with or preceding parkinsonism, ${ }^{2}$ associated with the triad of fluctuating attention, hallucinations and parkinsonism with recent inclusion of rapid eye movement (REM) sleep behavior disorder as a supportive criterion. ${ }^{3}$ By contrast, dementia occurring in the setting of well-established parkinsonism, pragmatically defined by at least 1 year of symptoms, is considered to define Parkinson's disease dementia (PDD), although this "1-year rule" remains contentious. ${ }^{4}$ The revised diagnostic MSA criteria continue to categorize MSA with predominant parkinsonism (MSA-P) or with predominant cerebellar ataxia (MSA-C). Clinical diagnosis of possible MSA requires rigorously-defined dysautonomia and parkinsonism that is poorly responsive to levodopa, or cerebellar ataxia with neuroimaging abnormalities representing a supporting feature. $^{5,6}$
While motor symptoms define parkinsonism, nonmotor features, including mild cognitive impairment (MCI), neuropsychiatric features, dysautonomia, and REM sleep behavior disorder, can precede synucleinopathy diagnosis ${ }^{7-9}$ and may enhance diagnostic accuracy. ${ }^{10}$ While bradykinesia and rigidity in PD respond to dopaminergic treatment, tremor, gait, and postural impairment do not always improve as consistently; less is known about levodopa response in DLB and MSA, though some response is possible, especially in early MSA-P. ${ }^{11,12}$ Nonmotor symptoms (NMS) do not consistently respond to dopaminergic therapy, ${ }^{13}$ while the response to motor symptoms becomes less complete as cognitive impairment worsens. ${ }^{14}$ Some features, such as sleepiness, orthostatic hypotension $(\mathrm{OH})$, and freezing of gait (FOG), may in fact be exacerbated by dopaminergic medications.

Falls are common in synucleinopathies and can lead to significant morbidity and mortality. This underscores the need

From the Division of Neurology, Department of Medicine, University of Alberta, Edmonton, Alberta, Canada

Received December 17, 2018. Final Revisions Submitted July 24, 2019. Date of Acceptance August 20, 2019.

Correspondence to: Fang Ba, Division of Neurology, Department of Medicine, University of Alberta, 7-112 Clinical Sciences Building, 11350 - 83 Avenue, Edmonton, Alberta, Canada T6G 2G3. Email: fb@ualberta.ca 
Table 1: Falls latency (duration from first symptom to falls onset) in the synucleinopathies

\begin{tabular}{l|c|c|c}
\hline & $\boldsymbol{N}$ & $\begin{array}{c}\text { Age at disease } \\
\text { onset, years } \\
\text { (range) }\end{array}$ & $\begin{array}{c}\text { Falls latency, } \\
\text { months (range) }\end{array}$ \\
\hline PD & 485 & $58(29-84)$ & $113(0-384)$ \\
\hline DLB & 60 & $69(40-87)$ & $51(0-287)$ \\
\hline MSA & 106 & $56(33-79)$ & $33(0-165)$ \\
\hline
\end{tabular}

Data adapted from refs. [19,20]

PD: Parkinson's disease; DLB: dementia with Lewy bodies; MSA: multiple system atrophy.

for fall risk assessment and the implementation of preventative measures in any patient with parkinsonism. Non-synucleinrelated conditions, such as corticobasal ganglionic degeneration and progressive supranuclear palsy (PSP), also feature falls and can be misdiagnosed as synucleinopathies. ${ }^{15}$ This review focuses on synucleinopathies since it is a distinct group of movement disorders with shared pathogenic features associated with parkinsonism, gait impairment, and dysautonomia that increase fall risk. The aim is to review modifiable risk factors as well as medical, surgical, and nonpharmacological approaches to the prevention and treatment of falls in these disorders.

\section{Falls Epidemiology in Synucleinopathies}

Falls are common in synucleinopathies. Thirty-five to $90 \%$ of PD patients fell at least once over 12 months (average 60.5\%), with two-thirds recurrent fallers. ${ }^{16}$ Likewise, those with DLB sustained sixfold more falls compared to healthy controls. ${ }^{17} \mathrm{In}$ MSA, frequent falls were the commonest milestone of disease advancement and mortality progression, with an estimated probability of at least daily falls of $23 \% 5$ years from disease onset, and years to death of 1-2 years when falls occur. ${ }^{18}$

Recurrent falls and postural instability (PI) are supportive clinical features of DLB and MSA, and conversely, are considered red flags early in the course of PD. Correspondingly, falls incidence is roughly double in DLB relative to those with PD without dementia. ${ }^{17,18}$ Studies assessing postmortem-confirmed parkinsonian disorders noted that the latency between symptom onset to recurrent falling was far shorter in DLB and MSA compared with PD (Table 1). The latency between recurrent falling and death was not significantly different between groups, suggesting that recurrent falls herald an advanced stage of disease with poor prognosis.

\section{Fall Risk Factors in PD, DLB, and MSA}

\section{Fall Risk Factors in PD}

Given the impact falls have in synucleinopathies, a systematic way to identify those most likely to fall would be ideal to proactively mitigate risk. Numerous risk factors have been proposed; however, the relative contribution of any factor in particular is difficult to assess given the interplay between them and their tendency to change over time. Many studies have devised prediction models for falling in $\mathrm{PD},{ }^{21-31}$ and although these have highlighted various risk factors, their relative degree of contribution is inconsistent for several reasons. Many studies rely on subjectively collected questionnaires or one-time neurological assessments. Often, falls are self-reported in fall diaries with considerable heterogeneity between subjects. Some studies evaluate not easily accessible or practical physiological measurements. ${ }^{32}$ Recently, a clinical prediction tool to discriminate future fallers from non-fallers was developed ${ }^{33}$ and validated, ${ }^{34,35}$ using a history of at least one fall within the past year, FOG in the past month, and slowed gait speed as fall risk determinants. This allows the simple classification of PD patients into low (17\%), moderate $(51 \%)$, and high $(85 \%)$ fall risk in the ensuing 6 months, which can be effectively communicated and introduce strategies for fall prevention. This provides a benchmark for the development for other predictive models but doesn't identify all factors that might be targeted for interventions. Other simple models, such as recent fall history, pull test, tandem gait and dyskinesias, and Frontal Assessment Battery (FAB), have also been examined. ${ }^{35,36}$

Preemptively identifying modifiable risk factors to implement preventative strategies is essential. Over the past decade, many small to moderately sized prospective studies have attempted to elucidate this by comparing potential risk factor profiles between fallers and non-fallers (Supplementary Table S1). Prior studies have been reviewed previously. ${ }^{16,37}$ The evidence for the prevention of falls through the remediation of these risk factors is reviewed in the next section.

Non-modifiable risk factors inconsistently associated with increased fall risk in PD include advanced age $\mathrm{e}^{22,26,27,30,38-45}$ and gender, ${ }^{21,22,24,27,38-44,46,47}$ although they are known risk factors in the general population. ${ }^{48}$ Conversely, the rate at which nonmotor and motor symptoms develop can depend on sex and age at diagnosis, with dramatic rates in the development of axial symptoms after age $70 .{ }^{49}$ Thus, the patient population studied may influence findings in observational studies. Other risk factors consistently associated with falls in PD include disease severity as measured by $\mathrm{H} \& \mathrm{Y}$ scale, $22,22,25-27,31,38,42-44,46,47,50-52$ UPDRS total score, $22,23,27,30,39,44-46,50,51,53$ and UPDRS motor subscore. $^{21-23,25,27,30,38,41,42,47,51,52,54,55}$ Studies where no association was found ${ }^{24,26,39,43,44,53}$ may be explained by the fact that as motor features progress, the fall risk decreases as the patient becomes more sedentary. Moreover, tremor might decrease leading to lower scores in the setting of worsening gait and PI subscores with paradoxically better overall scores in fallers. ${ }^{26}$ Similarly, proxies for disease severity, including higher levodopa equivalent doses ${ }^{22-24,26,27,30,39,42,44,47,52,53,55}$ and disease duration, have been variably identified as risk factors, ${ }^{21-23,27,30,31,38,40,42-44,46,47,50-55}$ although the degree of levodopa response is not usually directly assessed. Falls can be observed preceding diagnosis ${ }^{24,25}$ and prior to initiation of levodopa ${ }^{21}$ particularly in those with the postural instability and gait difficulties (PIGD) subtype. ${ }^{21,22,24,25,30,42,46}$ Injurious falls and hip fractures may in fact precede PD diagnosis by a decade or more. ${ }^{56}$

Certain motor symptoms and signs of parkinsonism are potentially modifiable risk factors. Numerous studies have identified impaired balance as a key risk factor by assessing composite measures of $\mathrm{PI}^{21,22,24,25,30,42,43,46,47,52-55,57}$ anticipatory balance maneuvers, ${ }^{22-25,27,31,41,42,44,52,55,57-59}$ reactive balance maneuvers, ${ }^{35,54,57-59}$ and slowed mobility. ${ }^{24-26,41,44,54,58}$ FOG is also reliably associated, ${ }^{21-23,27,35,42,43,47,50,54,55,58-60}$ while conversely, tremor, axial rigidity, and dyskinesias are not convincingly associated. ${ }^{22-24,27,30,31,50,54,55,58}$ 
Dementia is a significant fall risk factor in the general population and in $\mathrm{PD},{ }^{61}$ although data are less comprehensive in MCI. Some studies correlated increased fall risk with lower scores on global cognitive assessments ${ }^{21,23,30,41,50,58,60}$ while others have not. ${ }^{22,24-27,38,40,43,44,50,51,53,55}$ However, many studies excluded patients with cognitive impairment a priori based on mini-Mental State Exam (MMSE) screening (i.e., less than 24). ${ }^{62}$ This is problematic since MCI and dementia are common in $\mathrm{PD},{ }^{63}$ and the MMSE is insensitive to attention and executive function, both of which are more prominently affected in PD-related cognitive impairment. ${ }^{64}$ The few studies that examined specific cognitive domains found mixed data to suggest possible correlations with frontal, ${ }^{23,25,45,47,53,58}$ visuospatial, $^{25}$ working memory, ${ }^{24,31,58}$ verbal function, ${ }^{31,58}$ and dual-tasking impairment. ${ }^{40,41,54}$

$\mathrm{OH}$ is prevalent in PD and may have a reversible effect upon cognition secondary to CNS hypoperfusion. ${ }^{65} \mathrm{~A}$ few studies showed involvement of $\mathrm{OH}$ in falls. ${ }^{24,27,45,51,53}$ One recent study focusing on cardiovascular dysautonomia in PD fallers found an adjusted tenfold increased probability of falling in those with $\mathrm{OH} .{ }^{66}$ Dopaminergic medications can exacerbate $\mathrm{OH}$ and further increase fall risks. Likewise, one study investigating urinary dysfunction in PD fallers found mild (but not severe) urinary urgency was associated with a fivefold increased fall risk, ${ }^{51}$ presumably given the balance between the need to ambulate quickly versus the presence of activity and environmental factors.

With respect to neuropsychiatric symptoms, depression has been proposed as a potential factor, as it may influence motivation to ambulate in addition to psychomotor slowing, ${ }^{21,46,51}$ although numerous other studies have not found a correlation. ${ }^{24,26,39,40,43,44,47,53}$ Depression is a risk factor for falls in older people without PD. ${ }^{48}$

Other potentially modifiable risk factors include a fear of falling, which can be related to anxiety, ${ }^{24-26,30,39,42,44,46,47,52-55}$ impaired activities of daily living and reduced quality of life, ${ }^{22,24,26,27,30,31,38,39,42,46,50,52-55}$ reduced lower extremity strength, ${ }^{23,58}$ and sensory dysfunction. ${ }^{23,46,51,58}$

\section{Fall Risk Factors in DLB}

The onset of recurrent falling is much shorter in DLB relative to PD, with repeated falls a supportive criterion for DLB. Although both are neuropathologically characterized by Lewy bodies and Lewy neurites, their symptomatology and clinical course differ substantially. Similar to PD, the presenting features may be broadly subdivided into four categories: cognitive impairment, physical symptoms, dysautonomia, and neuropsychiatric phenomena.

DLB is the second-most common form of neurodegenerative dementia, after Alzheimer's disease (AD), and consequently, studies of fall risk tend to directly compare the two. Distinct from $\mathrm{AD}$, in which early anterograde amnesia is sine qua non, those with DLB display variable memory impairment; fluctuating cognitive impairment; and early dysfunction of attention, executive, and visuospatial domains. ${ }^{3}$ While a decline in global cognitive function is associated with increasing fall risk in heterogeneous general populations, ${ }^{67-70}$ a more careful examination of dementia subtypes has demonstrated a far greater fall risk and a shorter latency period from diagnosis to onset of recurrent falls in DLB relative to AD. ${ }^{17,71-73}$ The reason does not seem to be from a more aggressive rate of overall cognitive decline in DLB. ${ }^{73,74}$ More likely, the decline of specific cognitive domains characteristic of DLB, as well as autonomic and motor features, might explain the discrepancy. Patients with DLB have disproportionately more severe visuospatial impairment. ${ }^{75}$ This was substantiated by one study that demonstrated dysfunction in constructional praxis increased fall risk in DLB, and in particular, those without parkinsonism. ${ }^{76}$ Other disproportionately affected cognitive domains in DLB, such as judgment and executive function, likely contribute to fall risk as they do in the general population. ${ }^{70,77}$ The positive effects of cholinesterase inhibitors upon cognition and behavior ${ }^{78}$ may extend to reducing fall risk, although this is not clearly demonstrated. ${ }^{79}$ Finally, fluctuating cognition in DLB is likely to impact upon fall risk, as fall-related injuries may occur during cognitive "down" periods in patients without evidence of parkinsonism or PI. ${ }^{80}$

More severe parkinsonism is associated with an increased falls in DLB. ${ }^{81}$ However, while the essential motor features of PD can be present in DLB, they are not strictly required to diagnose "probable DLB," 3 and as only one cardinal feature is required to meet criteria for parkinsonism in DLB, many patients would not meet criteria for clinical PD. ${ }^{82}$ In fact, cross-sectional studies have shown that approximately $20 \%-30 \%$ of patients have minimal or no signs of parkinsonism during their disease course. ${ }^{83,84}$ When parkinsonism is present, extrapyramidal motor features in DLB more often take the form of prominent axial symptoms rather than resting tremor as compared with PD. ${ }^{85,86}$ Correspondingly, a cross-sectional analysis found that those with Lewy body dementias (either DLB or PDD) had a greater fall risk and poorer scores on gait and balance relative to those with AD. ${ }^{71}$ Other studies have similarly shown poorer scores on gait and balance when comparing those with DLB versus AD and PDD, and likewise correlated these measures to fall risk. ${ }^{87,88} \mathrm{~A}$ prospective assessment of baseline risk factors in DLB recapitulated these findings and noted that abnormalities in gait and balance correlated with increasing fall risk. ${ }^{17}$ FOG is usually a sign of advanced PD and is frequently seen in atypical parkinsonism, including DLB. ${ }^{89,90}$

The NMS profile of DLB includes dysautonomia, neuropsychiatric symptoms, and REM sleep behavior disorders. A prospective assessment of baseline risk factors in DLB demonstrated that fall risk was related to the duration of dementia, use of cardioactive medications, and dysautonomia. ${ }^{88}$ Dysautonomia, particularly $\mathrm{OH}$ and exaggerated carotid sinus reflex, is more common in DLB compared with PD and other forms of dementia, ${ }^{91,92}$ and together caused the majority of syncopal episodes in those with DLB in a prospective observational study. ${ }^{93}$ Part of this may relate to the exaggerated period of hypotension following orthostatic challenge seen in DLB relative to other forms of dementia. ${ }^{94}$ Furthermore, dysautonomia was associated with significantly reduced survival within 3 years of a prospective longitudinal study. ${ }^{95}$ Persistently untreated $\mathrm{OH}$ may in fact precipitate or worsen dementia secondary to prolonged regional cerebral hypoperfusion. ${ }^{96,97} \mathrm{OH}$ and consequent falls can be further exacerbated by medications used to treat the neuropsychiatric manifestations of DLB, including psychotropic medication, and the use of psychotropic medications is an independent risk factor in falls in DLB. ${ }^{17}$ Cholinesterase inhibitors may induce bradycardia and syncope leading to fall-related injuries including hip fractures in patients with dementia, ${ }^{98}$ which is of particular significance in DLB considering the association with neurocardiovascular instability. ${ }^{91}$ Benzodiazepines are often used to treat 
Table 2: Therapy interventions and monitoring of falls in PD and DLB

\begin{tabular}{l|l}
\hline Intrinsic & \multicolumn{1}{c}{ Extrinsic } \\
\hline Optimize medical treatment for PD & $\begin{array}{l}\text { Environmental assessment and } \\
\text { modification }\end{array}$ \\
\hline Cognitive strategies & Wearable sensors \\
\hline Surgical treatment - (DBS at novel targets) & Embedded home sensors \\
\hline Non-invasive brain stimulation & $\begin{array}{l}\text { Virtual reality training, combined with } \\
\text { complex motor tasks }\end{array}$ \\
\hline Exercise & \\
\hline Physiotherapy & \\
\hline
\end{tabular}

REM sleep behavior disorder but also increase falls risk and hip fractures in the elderly population. ${ }^{99}$ Finally, dopaminergic drugs are also well recognized to cause hypotension or exacerbations of $\mathrm{OH}^{100}$ that lead to increased falls risk.

\section{Fall Risk Factors in MSA}

Fall risks have not been as extensively studied in MSA when compared to PD, which may reflect the early onset and high frequency of falls in this disease ${ }^{19}$ in addition to its relative rarity. Moreover, its rapid progression, particularly early in the course of the disease, necessitates the use of gait aids and confinement to wheelchair by 3 and 5 years, respectively. ${ }^{101}$ One retrospective study examined fall risk factors in atypical parkinsonism, including MSA. ${ }^{20}$ In this study, univariate analysis distinguished fallers from non-fallers using clinical features of MSA including limb rigidity, speech disturbance, dysphagia, and pyramidal tract signs. Further, the latency to first fall was independently influenced by age of disease onset and PI. The presence of cerebellar signs, as seen prominently in MSA-C, is likely also to be a risk factor, particularly given the broad-based ataxic gait commonly associated with this condition, ${ }^{6}$ but was underrepresented in this study sample. Finally, dysautonomia was not found to be a fall risk factor; however, this is likely a reflection of its early and severe prominence in both fallers and non-fallers, particularly in the urogenital and cardiovascular domains. ${ }^{102}$

Other prominent features of MSA that may be early risk factors for falls may be extrapolated from the preceding discussions on PD and DLB. Motor risks include PI (89\% at presentation), FOG (38\%), postural tremor (54\%), and dystonia $(10 \%) .{ }^{102}$ Likewise, nonmotor potential risks include depression (41\% at presentation), executive dysfunction (49\%), and dementia $(4.5 \%){ }^{102,103}$

\section{Approaches to Fall Prevention}

Although the majority of the evidence toward disease management comes from studies in PD, there is substantial overlap in the challenges faced, and therefore, the strategies are broadly applicable to other synucleinopathies (Table 2). Pharmacological, nonpharmacological, and surgical treatment options are described later and are summarized in Table 3.

\section{Clinical Approaches to Fall Classification}

Key to establishing a treatment plan in such a multifactorial phenomenon is to classify falls to understand and manage risk. In practice, establishing fall circumstances can be challenging, as this is often self-reported and retrospective, and therefore subject to the vagaries of memory, ${ }^{141}$ particularly in a population with cognitive challenges. Moreover, it is important to document the events leading toward a fall, rather than simply assessing fall frequency, as the latter does not have a clear relationship with fall etiology. ${ }^{26}$ Instead, the use of fall diaries to record both the frequency and circumstances of falling can be successfully used, at least in those without major cognitive impairment. $^{142,143}$

Establishing the environment and type of movements leading to a fall is important, as for example, those falling during transitional movements or in the home tend to have a higher burden of disease than those who fall during higher-risk activities or in the community. ${ }^{26,38}$ Falls occurring during multitasking, at a particular time suggestive of cognitive fluctuations, or in the presence of neuropsychiatric disturbances might suggest the need for neurocognitive treatment. A review of medications and "on" or "off" status can be helpful for medication selection and titration. Preceding symptoms, such as presyncope or dizziness, may suggest the need for management of $\mathrm{OH}$, bearing in mind that $\mathrm{OH}$ can be asymptomatic. Finally, other mitigating circumstances, such as urinary urgency, proprioceptive loss, or visual impairment, can trigger management of comorbid disease.

Recently, a simplified approach toward falls classification was developed, which divides falls into those involving transitional movements (e.g., rising from a chair), complex motor activities (e.g., skiing), and combined movements (e.g., garden work). ${ }^{144}$ Describing falls in this manner may simplify the approach toward management by categorizing physical differences between fallers and thereby allowing the detection and targeting of fall risk factors. For example, those with consistent transitional falls may benefit from strength or simple balance training, while those with consistent falls during combined movements may benefit from targeted neurocognitive strategies.

\section{Optimizing Medical Management of Parkinsonism}

Levodopa remains the agent of choice in the treatment of parkinsonism, particularly in PD, although short-lived, if less robust, responses are seen in as many as half of patients with DLB and MSA. ${ }^{11,12,102}$ However, PI may respond less reliably, ${ }^{48,49,145}$ and fall risk and PI may persist and progressively worsen despite levodopa. ${ }^{146}$ This may, in part, arise from levodopa-induced dyskinesias. ${ }^{147}$ In patients responding well to antiparkinsonian drugs (i.e., $>30 \%$ change in UPDRS-III with treatment), axial features were found to respond partially to levodopa. ${ }^{148}$ Decreased levodopa efficacy with disease progression has been attributed to worsening axial symptoms (i.e., gait disorders and PI) ${ }^{145,149}$ and is considered to result from the increasing severity of non-dopaminergic deficits affecting brain regions and systems localized outside of the striatal output pathways. ${ }^{150}$ Conversely, levodopa improves rigidity and bradykinesia, and thus enhances patient mobility. As PD fallers have higher impulsivity scores compared to nonfallers, ${ }^{151}$ this imbalance between the persistence of PI and improved ambulation with levodopa can potentially increase the likelihood of falling. ${ }^{26}$

FOG is common in synucleinopathies and remains difficult to treat. 89,90 In PD, FOG can occur in the "on" or "off" states, 
Table 3: Pharmacological, nonpharmacological, and surgical interventions

\begin{tabular}{|c|c|c|c|}
\hline $\begin{array}{l}\text { Medication/ } \\
\text { treatment }\end{array}$ & Effects & Reference & $\begin{array}{l}\text { Level of } \\
\text { evidence }\end{array}$ \\
\hline \multicolumn{4}{|l|}{ DA agonists } \\
\hline Ropinirole & $\uparrow$ incidence of FOG vs. levodopa & 104 & $\mathrm{~A} 2$ \\
\hline Pramipexole & $\uparrow$ incidence of FOG vs. levodopa & 105 & $\mathrm{~A} 2$ \\
\hline \multicolumn{4}{|l|}{ MAO-B inhibitors } \\
\hline Selegiline & $\downarrow$ risk of FOG & 106,107 & $\mathrm{~A} 2$ \\
\hline Rasagiline & $\downarrow$ risk of FOG & 108 & A2 \\
\hline \multicolumn{4}{|l|}{ NMDA antagonists } \\
\hline Amantadine & \begin{tabular}{|c|} 
Some evidence for $\downarrow$ fall risk in PSP; \\
inconsistent data in PD
\end{tabular} & $109-112$ & $\mathrm{~B}, \mathrm{C}$ \\
\hline \multicolumn{4}{|l|}{$N E$ precursor } \\
\hline Droxidopa & $\begin{array}{l}\downarrow \text { fall risk possibly due to } \\
\text { improvement in postural } \\
\text { hypotension }\end{array}$ & 113,114 & $\mathrm{~A} 2, \mathrm{~B}$ \\
\hline \multicolumn{4}{|l|}{ Anticholinergics } \\
\hline Donepezil & $\begin{array}{l}\downarrow \text { fall risk in PD patients without } \\
\text { FOG }\end{array}$ & 115 & B \\
\hline Rivastigmine & Improvement in gait parameters & 116 & B \\
\hline Any drug & $\begin{array}{l}\uparrow \begin{array}{l}\uparrow \text { emergency room visits, admissions, } \\
\text { and fractures }\end{array} \\
\end{array}$ & 117 & $\mathrm{C}$ \\
\hline \multicolumn{4}{|l|}{ Antidepressants } \\
\hline Any drug & $\uparrow$ fall risk & 118 & B \\
\hline \multicolumn{4}{|l|}{ CNS stimulants } \\
\hline Methylphenidate & $\begin{array}{l}\text { Inconsistent benefit; effect thought to } \\
\text { be due to improved attention }\end{array}$ & $119-121$ & $\mathrm{~B}, \mathrm{C}$ \\
\hline \multicolumn{4}{|l|}{ DBS stimulation } \\
\hline STN or GPi & $\begin{array}{l}\text { Levodopa-resistant postural } \\
\text { instability and falls are unlikely to } \\
\text { respond to DBS, and may worsen. } \\
\text { If seen, there is unsustained benefit } \\
\text { in posture, FOG, and gait }\end{array}$ & 122,123 & $\mathrm{~A} 1$ \\
\hline PPN & Inconsistent data & $124-126$ & B \\
\hline $\mathrm{SNr}$ & $\begin{array}{l}\text { Limited data suggest improvement in } \\
\text { FOG but not in other axial } \\
\text { symptoms if combined with STN } \\
\text { stimulation }\end{array}$ & 127 & B \\
\hline Cognitive training & $\begin{array}{l}\text { Dual-task training and virtual reality } \\
\text { training may improve gait speed } \\
\text { in elderly adults. Unknown effect } \\
\text { in PD }\end{array}$ & $128-131$ & B \\
\hline \multicolumn{4}{|l|}{ Physiotherapy } \\
\hline Tai chi & $\begin{array}{l}\text { Tai chi improved balance and } \\
\text { reduced falls in mild-moderate PD } \\
\end{array}$ & 132 & A2 \\
\hline $\begin{array}{c}\text { Resistance } \\
\text { training }\end{array}$ & $\begin{array}{l}\text { Resistance strength training reduced } \\
\text { falls in mild-moderate PD } \\
\end{array}$ & 133 & B \\
\hline Balance training & \begin{tabular}{|l} 
Outpatient or home-based \\
physiotherapy programs may \\
reduce the number of injurious falls
\end{tabular} & $134-138$ & B \\
\hline Dance & $\begin{array}{l}\text { Tango dancing may improve } \\
\text { mobility and motor severity in PD }\end{array}$ & 139 & B \\
\hline
\end{tabular}

Table 3: (Continued)

\begin{tabular}{l|l|c|c}
\hline $\begin{array}{l}\text { Medication/ } \\
\text { treatment }\end{array}$ & Effects & Reference & $\begin{array}{c}\text { Level of } \\
\text { evidence }\end{array}$ \\
\hline $\begin{array}{l}\text { Occupational } \\
\text { therapy }\end{array}$ & $\begin{array}{l}\text { Insufficient evidence supports the use } \\
\text { of occupational therapy in falls } \\
\text { prevention }\end{array}$ & 140 & $\mathrm{D}$ \\
\hline
\end{tabular}

A1=meta-analysis containing at least some trials with evidence level A2, with consistency in trial results; A2=good quality randomized comparative clinical trials (randomized double-blind controlled trials) of sufficient size and consistency; $\mathrm{B}=$ moderate (weak) quality randomized clinical trials of insufficient size or other comparative trials (non-randomized trials, cohort studies, patient-control studies); $\mathrm{C}=$ non-comparative trials; $\mathrm{D}=$ expert opinion.

with off-freezing potentially improving with dopaminergic medications. Levodopa has been shown to be a better agent of choice compared to dopamine agonists: an increased risk of freezing was observed in a pramipexole group compared with the levodopa group (hazard ratio 1:7) in a phase-III, prospective, double-blind, placebo-controlled trial. ${ }^{152}$ A similar observation was reported with ropinirole in patients with early PD in a prospective, double-blind, placebo-controlled trial with a 5-year follow-up. ${ }^{104}$ Selegiline was effective in reducing the risk of developing FOG, ${ }^{106}$ and in decreasing the number of patients who develop FOG as a late complication of disease progression in a 2-year prospective follow-up. ${ }^{107}$ Rasagiline showed a 1.17 point improvement on the FOG-Questionnaire (FOG-Q) total score, in a prospective, double blind, placebo-controlled study. ${ }^{108}$ In both studies, however, falls were not directly addressed, and therefore the clinical significance is unclear. In the case of DLB, dopamine agonists are not preferable because of their propensity to cause hallucinations and somnolence. ${ }^{153}$ Moreover, monoamine oxidase type-B inhibitors may cause $\mathrm{OH}$ and thus might precipitate falls. There are conflicting results regarding Amantadine in FOG and subsequent falls risk, but there is some evidence for fall risk reduction in PSP. ${ }^{109}$ The norepinephrine precursor, droxidopa, was shown to reduce fall risk in $\mathrm{PD},{ }^{113}$ with the mechanism attributed to improvement in postural hypotension, though other effects have not been extensively examined.

\section{Optimizing Surgical Management}

Multiple randomized controlled studies have demonstrated that deep brain stimulation (DBS) of the subthalamic nucleus (STN) and globus pallidus interna (GPi) is superior to medical treatment alone in the treatment of a number of cardinal PD symptoms and motor complications from therapy. ${ }^{154-156}$ The benefit of DBS on axial symptoms, however, is less clear. ${ }^{157}$ Several reports have indicated improvement of posture, gait, and balance control after STN- or GPi-DBS, when these symptoms were responsive to levodopa treatment before DBS surgery ${ }^{158-163}$ however, the benefit on PI and gait is not sustained. ${ }^{158}$ Moreover, a significant number of patients report post-operative worsening of gait despite concurrent improvement in motor scores and global outcomes after bilateral STN-DBS. ${ }^{164}$ Further, falls risk has been demonstrated to increase and levodopa-resistant FOG to persist or worsen. ${ }^{165-171}$ To complicate matters further, stimulation 
parameters (i.e., high-frequency stimulation) can also lead to adverse axial effects in patients.

The pedunculopontine nucleus (PPN) is considered a key component of the mesencephalic locomotor region (MLR). ${ }^{172}$ Widespread projections involving the PPN include direct glutamatergic inputs from the motor cortex, and GABAergic inputs from substantia nigra, GPi, STN, and deep nuclei of the cerebellum. ${ }^{173}$ Previous work suggests that the PPN is underactive in PD due to degeneration and inhibition, and that this underactivity relates to axial motor impairment. ${ }^{174}$ Since the first report of PPN-DBS, ${ }^{175}$ multiple studies have shown clinical improvement in patients with PD who have PI and FOG, but results have been variable. ${ }^{176-179}$ Despite more than 10 years of experience, PPN-DBS remains experimental and the number of implanted patients remains limited since the outcome varies considerably. A heterogeneous dataset has been published so far including case reports, open label series, double-blinded single time point single-center study, and longer-term double-blinded studies. The heterogeneous study designs, differences in outcome measures to assess FOG, falls, and PI, the different targeting strategies and stimulation sites (caudal vs. rostral PPN), the variability in DBS settings (including unilateral PPN vs. bilateral, lone bilateral PPN-DBS, and combined bilateral PPN-DBS with other targets, i.e., STN or caudal zona Incerta) may explain the inconsistencies. In addition, different stimulation parameters contribute to variable results. For instance, low-frequency PPN-DBS can improve axial motor symptoms presumably by partly reversing PPN underactivity. ${ }^{178,180}$ More precise targeting strategies with improved technology (i.e., improved imaging and programming) are required. Structural and functional neuroimaging may have a role in patient selection to determine if PPN degeneration is too severe for PPN-DBS to work. ${ }^{181}$ In addition, to improve axial symptoms, that is, FOG, multitarget DBS strategies have been trialed allowing the modulation of cortico-basal ganglia loops, and subsequently aiming to improve falls. ${ }^{182}$ Since falls and gait impairment are likely related to multiple failing neural circuits, combined PPN and STN stimulation may have greater beneficial effects on gait and PI than either target alone. ${ }^{176}$ Targeting multiple sites can potentially synchronize different circuits and promote neuroplasticity; however, the risk/benefit trade-offs have yet to be determined. ${ }^{183}$ Although there is scarce evidence of PPN-DBS reducing falls and FOG in PD, whether and how to modulate the PPN remains to be determined.

The substantia nigra pars reticulata $(\mathrm{SNr})$ is another key player in the MLR, via its significant efferent GABAergic input to the PPN. ${ }^{184}$ Axial motor symptomatology, including gait impairment and PI, responds favorably to $\mathrm{SNr}$ stimulation in the literature. ${ }^{127,185-187}$ One of the more recent double-blind, cross-over, randomized controlled trials with combined STN and $\mathrm{SNr}$ stimulation showed significant improvement in FOG, but not in other axial symptoms when compared to STN-DBS alone. ${ }^{127}$ With SNr-DBS, one should be cautious about the possibility of worsening akinesia, as increased immobility and recurrent falls were reported with combined $\mathrm{STN}$ and $\mathrm{SNr}$ stimulation. $^{127}$

Spinal cord stimulation has recently been investigated in PD. ${ }^{188}$ Although presently studied only in small open-label case studies, there has been early evidence to suggest improvement in FOG and PI, ${ }^{189,190}$ although falls were not assessed as an outcome.

\section{Managing Orthostatic Hypotension}

The approach to treating $\mathrm{OH}$ includes correcting aggravating factors (discontinuing hypertensive medications and correcting anemia) and implementing nonpharmacological measures and pharmacological treatment. Levodopa and dopamine agonists have been variably reported to contribute toward $\mathrm{OH}$ (reviewed in $^{191}$ ), which should be reviewed with patients when making dose adjustments. Nonpharmacological measures with volume expansion, lifestyle management, activity level, and diet adjustment are first-line recommendations. Physical counter-maneuvers are helpful. $^{192}$

In patients with severe $\mathrm{OH}$, pharmacologic therapies are advisable to minimize the fall risks leading to injuries. ${ }^{193}$ Efficacious agents include the synthetic mineralocorticoid fludrocortisone and the pressor agents midodrine or droxidopa. All drugs that raise blood pressure when standing also raise blood pressure when supine, increasing the risk of supine hypertension. Although there are no specific reports on cardio- and cerebrovascular adverse events induced by supine hypertension in this cohort, one should be cautious about this potential side effect.

\section{Cognitive Strategies}

Emerging evidence indicates that deficits in multiple cognitive domains, such as attention, executive function, and working memory, are associated with low gait velocity, stability, and falls. ${ }^{60}$ Medical treatment addressing the motor deficits in PD dementia and DLB can have cognitive side effects (i.e., decreasing verbal short-term memory, attention, reaction time and set-shifting, increasing impulsivity/worsened decision-making, impaired distractor resistance, hallucinations) that increase the propensity to fall. ${ }^{194}$ Dopamine agonists and anti-cholinergics should be avoided in this population, given adverse effects on alertness and general cognition, and less improvement in overall motor function compared to levodopa. DLB patients are at heightened risk for complications of drug therapy, since they are prone to psychosis triggered by dopaminergic therapies and more susceptible to side effects of antipsychotics used to treat hallucinations. Atypical agents, such as olanzapine or quetiapine, are not risk-free but are preferred when an antipsychotic drug is indicated. ${ }^{153,195}$ While quetiapine has less propensity to worsen parkinsonism, it has sedating and anti-cholinergic effects that might increase fall risk.

Nonpharmacologic treatment strategies for DLB are the same as in other dementia syndromes, ${ }^{196,197}$ with a focus on ameliorating environmental, medical, psychological, and social factors that may exacerbate problem behaviors leading to falls. Many interventions for fall prevention do not translate successfully from cognitively normal older adults to those with dementia, ${ }^{198}$ likely due to different underlying mechanisms for falls and treatments unable to adequately address cognitive deficits. Studies using nonpharmacological methods, including single motor task, dual-task, and complex motor task training, have shown some benefit reducing fall risk; ${ }^{128-131}$ however, results vary from study to study. Large-scale studies with more standardized protocols are needed.

Cholinesterase inhibitors can offer clinically meaningful benefits to patients with cognitive issues, particularly in the domains of apathy, confusion, hallucinations, and somnolence, ${ }^{199}$ and thus may improve fall risk. A small trial of donepezil suggested a reduction of falls in PD patients without FOG. ${ }^{115}$ Another study 
showed improvements in gait parameters, but may have been inadequately powered to examine the impact on falls. ${ }^{116}$ Memantine was investigated in patients with mild to moderate PD and DLB, with cognitive measures improving in the memantine group, but increased falls was a documented adverse effect. $^{200,201}$

Conversely, anti-cholinergic burden is associated with adverse events, including emergency room visits, fractures, and falls. ${ }^{117}$ Consistent with studies in older patients, antidepressants are associated with increased fall risk in $\mathrm{PD},{ }^{118}$ but it is not clear if this is related to comorbid pathology or a medication effect. Methylphenidate was shown to improve FOG in PD presumably through improving attention, ${ }^{119,120}$ although a randomized clinical trial showed negative results. ${ }^{121}$

\section{Exercise/Physiotherapy}

There is abundant evidence showing the benefits of physical activity for $\mathrm{PD}$, and exercise can regulate neurotrophic factors and therefore potentially promote neuroprotection in PD. ${ }^{202,203}$ Strength and balance training can reduce falls among the community-dwelling elderly. ${ }^{204-208}$ Rhythmic visual or auditory clues $^{209-211}$ and mental singing during walking may also improve gait in PD. ${ }^{212}$ Randomized control trials have shown falls reduction with Tai Chi, ${ }^{132}$ and exercise programs for muscle strengthening and movement strategies. ${ }^{133}$

Physical therapy can improve fall prevention, ${ }^{134-136}$ but benefit may be limited and short-lasting. ${ }^{137,138}$ Dosage, training intensity, and duration may also affect results. A recent randomized trial of home program with strength and movement strategy training and falls education did not prevent falls. ${ }^{213}$ Dance therapy can be beneficial and may have longer-lasting effects. ${ }^{139,214,215}$ In particular, tango training improved mobility and other motor domains. ${ }^{139}$

One should be cautious in applying the results of therapeutic intervention studies to practice. Regular exercise, physiotherapy, and dance are helpful in mobility, but the right dosage and type of exercise should be individualized. Future studies should also focus on therapy content, repetitions, and effective duration, to optimize outcomes and cost-effectiveness for PD patients to further guide treatment. Falls should be included as on outcome in such studies.

\section{Risk Reduction in Osteoporosis}

PD patients are older and therefore have a higher risk for metabolic bone disease. This predisposes PD patients to fall-related injuries, including fractures. ${ }^{216,217}$ There are no specific guidelines related to management of osteoporosis and PD. A combination of bisphosphonates and vitamin D is recommended along with regular intake of calcium-containing food or supplements. ${ }^{218}$ Medical treatment is mainly based on computed X-ray densitometry (DEXA; T score $<-2.5$ ) and FRAX scores (10-year risk for fracture $>3 \%$ hip, $>20 \%$ of any major osteoporotic fracture). ${ }^{218}$ Two main types of pharmacological treatments are available to treat patients with osteoporosis: antiresorptive agents and anabolic agents. Dietary and nutritional manipulation is important, and vitamin D, B12, and folate status needs to be addressed and corrected if required. Lifestyle-related management, including smoking cessation and decreasing alcohol consumption and exercise, should be encouraged.

\section{Extrinsic Risk Reduction}

For PD, PDD, DLB, and MSA patients, fall prevention can benefit from occupation therapy input for improvement of home environment. This includes footwear, floor slipperiness, creating safe spaces and familiarization with furniture layouts, lighting, handrails conditions, bedroom/bathroom/kitchen adaptations. ${ }^{219}$ Patient education for behavioral adaptations is also essential to avoid multitasking and to take time with postural change to prevent postural dizziness.

\section{Other Risk Factors}

Several studies have identified the need for multimodal interdisciplinary methods for fall prevention and the need for more accurate risk assessment instruments. ${ }^{206,220-223}$ Multimodal assessments with targeted intervention reduced fall risk by $37 \%$, and exercise interventions reduced fall risk by $14 \% .{ }^{206} \mathrm{~A}$ meta-analysis identified a benefit on fall prevention in the community when individualized management tailored to address individual risk factors was added to exercise interventions. ${ }^{224}$

Other individual prevention strategies include cataract surgery and cardiac pacing. Cataracts are common in PD and PD-related disorders, ${ }^{225}$ and cataract disease is associated with a higher risk of developing PD. ${ }^{226}$ Cataract surgery for the first eye was found to reduce the fall rate by $34 \%$ in general population, but not the number of fallers. ${ }^{227}$ Moreover, surgery for the second eye did not reduce the fall rate further. Cardiac pacemakers in patients with cardio-inhibitory carotid sinus hypersensitivity reduced fall rate by $58 \%$, but not the number of fallers. ${ }^{228,229}$ For MSA with significant dysautonomia, cardiopulmonary arrest can occur. $^{230,231}$ Physicians should carefully review the history and risk factors and assess patients for indications for cardiac pacing.

\section{Novel Experimental Approaches to Falls Prevention}

\section{Wearable Sensors}

Wearable sensors (accelerometers and gyroscopes) have been used to test mobility. Gait and balance analysis can be extracted through daily activities for a real-time fall risk assessment. ${ }^{232-234}$ Such evaluations are potentially more sensitive than conventional tests for recording activity. ${ }^{235,236}$ Embedded home sensors are another approach to continuously monitor fall risk. ${ }^{237,238}$ Experimental motion sensors to feedback and help with rehabilitation have been used. Virtual reality training, combined with complex motor tasks, has also been shown to provide some benefit to falls prevention. $^{239}$

\section{Non-Invasive Stimulation}

Non-invasive brain stimulation techniques, such as repetitive transcranial magnetic stimulation (rTMS), have been trialed in various neurologic and psychiatric disorders. ${ }^{240}$ One recent metaanalysis demonstrated that rTMS can improve motor symptoms in PD with a moderate effect size. ${ }^{241}$ However, few rTMS studies have focused on FOG and falls in PD. ${ }^{242-246}$ One study with highfrequency rTMS over the lower leg primary motor cortex showed 
significant reduction in subjective FOG and improved gait performance. ${ }^{246}$ However, results are inconsistent across studies with different stimulation targets, frequencies, and parameters having been applied. Further well-designed, large-scale studies are needed.

Transcranial direct current stimulation (tDCS) is another non-invasive stimulation technique. To date, a few studies have shown some benefit of tDCS in FOG. A double-blind, crossover, randomized sham-controlled study showed that applying 20-minute-long anodal $2 \mathrm{~mA}$ tDCS sessions on M1 during rest over 5 consecutive days significantly reduced dopamine-resistant FOG in 10 PD patients, and the benefit persisted at 1-month follow-up. $^{247}$ Simultaneous stimulation over M1 and left dorsolateral prefrontal cortex with tDCS was able to modulate consecutive motor and cognitive function and further improved FOG in 20 PD individuals with FOG when compared to sham or tDCS of either target alone. ${ }^{248}$ In practice, given the simplicity of the technology and affordability of tDCS compared to TMS, the former may be a safer, more cost-efficient tool for treatment once stronger evidence is established.

\section{Future Directions}

The successful future treatment and research of falls in synucleinopathies will need to consider and integrate cognitive, behavioral, pharmacological, device-based and surgical treatments along with the support of a multidisciplinary team. Further research examining functional neuroanatomy and neurochemistry as well as novel imaging modalities will help with our understanding of the pathophysiology underlying gait disorders and falls, and guide better treatment strategies in the future. Clinical trials of interventions should include falls as an outcome and safety measure.

\section{Disclosures}

The authors have no relevant disclosures.

\section{Statement of Authorship}

All authors are responsible for writing the manuscript, for discussions and for reviewing the manuscript.

\section{Supplementary Material}

To view supplementary material for this article, please visit https://doi.org/10.1017/cjn.2019.287.

\section{REFERENCES}

1. Postuma RB, Berg D, Stern M, et al. MDS clinical diagnostic criteria for Parkinson's disease. Mov Disord. 2015;30(12):1591-601.

2. McKeith IG, Dickson DW, Lowe J, et al. Diagnosis and management of dementia with Lewy bodies: third report of the DLB Consortium. Neurology. 2005;65(12):1863-72.

3. McKeith IG, Boeve BF, Dickson DW, et al. Diagnosis and management of dementia with Lewy bodies: fourth consensus report of the DLB Consortium. Neurology. 2017;89(1):88-100.

4. Postuma RB, Berg D, Stern M, et al. Abolishing the 1-year rule: how much evidence will be enough? Mov Disord. 2016;31(11):1623-7.

5. De Pablo-Fernandez E, Lees AJ, Holton JL, Warner TT. Prognosis and neuropathologic correlation of clinical subtypes of Parkinson disease. JAMA Neurol. 2019;76(4):470-9.

6. Gilman S, Wenning GK, Low PA, et al. Second consensus statement on the diagnosis of multiple system atrophy. Neurology. 2008;71(9):670-6.
7. Tolosa E, Gaig C, Santamaria J, Compta Y. Diagnosis and the premotor phase of Parkinson disease. Neurology. 2009;72(7 Suppl):S12-20.

8. Aarsland D, Bronnick K, Larsen JP, Tysnes OB, Alves G, Norwegian ParkWest Study G. Cognitive impairment in incident, untreated Parkinson disease: the Norwegian ParkWest study. Neurology. 2009;72(13):1121-6.

9. Iranzo A, Tolosa E, Gelpi E, et al. Neurodegenerative disease status and post-mortem pathology in idiopathic rapid-eye-movement sleep behaviour disorder: an observational cohort study. Lancet Neurol. 2013;12(5):443-53.

10. Galvin JE. Improving the clinical detection of Lewy body dementia with the Lewy body composite risk score. Alzheimers Dement (Amst). 2015;1(3):316-24.

11. Lucetti C, Logi C, Del Dotto $P$, et al. Levodopa response in dementia with Lewy bodies: a 1-year follow-up study. Parkinsonism Relat Disord. 2010;16(8):522-6.

12. Hughes AJ, Colosimo C, Kleedorfer B, Daniel SE, Lees AJ. The dopaminergic response in multiple system atrophy. J Neurol Neurosurg Psychiatry. 1992;55(11):1009-13.

13. Schaeffer E, Berg D. Dopaminergic therapies for non-motor symptoms in Parkinson's disease. CNS Drugs. 2017;31(7): 551-70.

14. Alty JE, Clissold BG, McColl CD, Reardon KA, Shiff M, Kempster PA. Longitudinal study of the levodopa motor response in Parkinson's disease: relationship between cognitive decline and motor function. Mov Disord. 2009;24(16):2337-43.

15. Borm C, Krismer F, Wenning GK, et al. Axial motor clues to identify atypical parkinsonism: a multicentre European cohort study. Parkinsonism Relat Disord. 2018;56:33-40.

16. Allen NE, Schwarzel AK, Canning CG. Recurrent falls in Parkinson's disease: a systematic review. Parkinsons Dis. 2013;2013:906274

17. Allan LM, Ballard CG, Rowan EN, Kenny RA. Incidence and prediction of falls in dementia: a prospective study in older people. PLoS One. 2009;4(5):e5521.

18. O'Sullivan SS, Massey LA, Williams DR, et al. Clinical outcomes of progressive supranuclear palsy and multiple system atrophy. Brain. 2008;131(Pt 5):1362-72.

19. Wenning GK, Ebersbach G, Verny M, et al. Progression of falls in postmortem-confirmed parkinsonian disorders. Mov Disord Soc. 1999;14(6):947-50.

20. Williams DR, Watt HC, Lees AJ. Predictors of falls and fractures in bradykinetic rigid syndromes: a retrospective study. J Neurol Neurosurg Psychiatry. 2006;77(4):468-73.

21. Hiorth YH, Alves G, Larsen JP, Schulz J, Tysnes OB, Pedersen KF. Long-term risk of falls in an incident Parkinson's disease cohort: the Norwegian ParkWest study. J Neurol. 2017;264(2):364-72.

22. Kerr GK, Worringham CJ, Cole MH, Lacherez PF, Wood JM, Silburn PA. Predictors of future falls in Parkinson disease. Neurology. 2010;75(2):116-24.

23. Latt MD, Lord SR, Morris JGL, Fung VSC. Clinical and physiological assessments for elucidating falls risk in Parkinson's disease. Mov Disord. 2009;24(9):1280-9.

24. Lord S, Galna B, Yarnall AJ, Coleman S, Burn D, Rochester L. Predicting first fall in newly diagnosed Parkinson's disease: insights from a fall-naïve cohort. Mov Disord. 2016;31(12):1829-36.

25. Lord S, Galna B, Yarnall AJ, et al. Natural history of falls in an incident cohort of Parkinson's disease: early evolution, risk and protective features. J Neurol. 2017;264(11):2268-76.

26. Mactier K, Lord S, Godfrey A, Burn D, Rochester L. The relationship between real world ambulatory activity and falls in incident Parkinson's disease: influence of classification scheme. Parkinsonism Relat Disord. 2015;21(3):236-42.

27. Matinolli M, Korpelainen JT, Sotaniemi KA, Myllylä VV, Korpelainen R. Recurrent falls and mortality in Parkinson's disease: a prospective two-year follow-up study. Acta Neurol Scand. 2011;123(3):193-200.

28. Pickering RM, Grimbergen YAM, Rigney U, et al. A meta-analysis of six prospective studies of falling in Parkinson's disease. Mov Disord. 2007;22(13):1892-900. 
29. Schrag A, Choudhury M, Kaski D, Gallagher DA. Why do patients with Parkinson's disease fall? A cross-sectional analysis of possible causes of falls. NPJ Parkinson's Dis. 2015;1(1):15011.

30. Chou KL, Elm JJ, Wielinski CL, et al. Factors associated with falling in early, treated Parkinson's disease: the NET-PD LS1 cohort. J Neurol Sci. 2017;377:137-43.

31. Parashos SA, Bloem BR, Browner NM, et al. What predicts falls in Parkinson disease?: observations from the Parkinson's Foundation registry. Neurol Clin Pract. 2018;8(3):214-22.

32. Creaby MW, Cole MH. Gait characteristics and falls in Parkinson's disease: a systematic review and meta-analysis. Parkinsonism Relat Disord. 2018;57:1-8.

33. Paul SS, Canning CG, Sherrington C, Lord SR, Close JC, Fung VS. Three simple clinical tests to accurately predict falls in people with Parkinson's disease. Mov Disord. 2013;28(5):655-62.

34. Duncan RP, Cavanaugh JT, Earhart GM, et al. External validation of a simple clinical tool used to predict falls in people with Parkinson disease. Parkinsonism Relat Disord. 2015;21(8):960-3.

35. Lindholm B, Nilsson MH, Hansson O, Hagell P. External validation of a 3-step falls prediction model in mild Parkinson's disease. J Neurol. 2016;263(12):2462-9.

36. Lindholm B, Eek F, Skogar O, Hansson EE. Dyskinesia and FAB score predict future falling in Parkinson's disease. Acta Neurol Scand. 2019.

37. Canning CG, Paul SS, Nieuwboer A. Prevention of falls in Parkinson's disease: a review of fall risk factors and the role of physical interventions. Neurodegener Dis Manag. 2014;4(3):203-21.

38. Lamont RM, Morris ME, Menz HB, McGinley JL, Brauer SG. Falls in people with Parkinson's disease: a prospective comparison of community and home-based falls. Gait Posture. 2017;55(April):62-7.

39. Gazibara T, Kisic Tepavcevic D, Svetel M, et al. Near-falls in people with Parkinson's disease: circumstances, contributing factors and association with falling. Clin Neurol Neurosurg. 2017;161(July):51-5.

40. Heinzel S, Maechtel M, Hasmann SE, et al. Motor dual-tasking deficits predict falls in Parkinson's disease: a prospective study. Parkinsonism Relat Disord. 2016;26:73-7.

41. Smulders K, Esselink RA, Weiss A, Kessels RP, Geurts AC, Bloem BR. Assessment of dual tasking has no clinical value for fall prediction in Parkinson's disease. J Neurol. 2012;259(9): 1840-7.

42. Cole MH, Rippey J, Naughton GA, Silburn PA. Use of a short-form balance confidence scale to predict future recurrent falls in people with Parkinson disease. Arch Phys Med Rehabil. 2016;97(1):152-6.

43. Mak MKY, Auyeung MM. The Mini-BESTest can predict parkinsonian recurrent fallers: a 6-month prospective study. J Rehabil Med. 2013;45(6):565-71.

44. Mak MK, Pang MY. Parkinsonian single fallers versus recurrent fallers: different fall characteristics and clinical features. J Neurol. 2010;257(9):1543-51.

45. Allcock LM, Rowan EN, Steen IN, Wesnes K, Kenny RA, Burn DJ. Impaired attention predicts falling in Parkinson's disease. Parkinsonism Relat Disord. 2009;15(2):110-5.

46. Voss TS, Elm JJ, Wielinski CL, et al. Fall frequency and risk assessment in early Parkinson's disease. Parkinsonism Relat Disord. 2012;18(7):837-41.

47. Mak MK, Wong A, Pang MY. Impaired executive function can predict recurrent falls in Parkinson's disease. Arch Phys Med Rehabil. 2014;95(12):2390-5.

48. Deandrea S, Lucenteforte E, Bravi F, Foschi R, La Vecchia C, Negri E. Risk factors for falls in community-dwelling older people: a systematic review and meta-analysis. Epidemiology. 2010;21(5):658-68.

49. Prange S, Danaila T, Laurencin C, et al. Age and time course of long-term motor and nonmotor complications in Parkinson disease. Neurology. 2019;92(2):e148-60.

50. Rudzinska M, Bukowczan S, Stozek J, et al. The incidence and risk factors of falls in Parkinson disease: prospective study. Neurol Neurochir Pol. 2013;47(5):431-7.
51. Sakushima K, Yamazaki S, Fukuma S, et al. Influence of urinary urgency and other urinary disturbances on falls in Parkinson's disease. J Neurol Sci. 2016;360:153-7.

52. Almeida LR, Valenca GT, Negreiros NN, Pinto EB, OliveiraFilho J. Comparison of self-report and performance-based balance measures for predicting recurrent falls in people with Parkinson disease: cohort study. Phys Ther. 2016;96(7): 1074-84.

53. Kataoka H, Ueno S. Low FAB score as a predictor of future falling in patients with Parkinson's disease: a 2.5-year prospective study. J Neurol. 2015;262(9):2049-55.

54. Lindholm B, Hagell P, Hansson O, Nilsson MH. Prediction of falls and/or near falls in people with mild Parkinson's disease. PLoS One. 2015;10(1):e0117018.

55. Almeida LR, Sherrington C, Allen NE, et al. Disability is an independent predictor of falls and recurrent falls in people with Parkinson's disease without a history of falls: a one-year prospective study. J Parkinsons Dis. 2015;5(4):855-64.

56. Nyström H, Nordström A, Nordström P. Risk of injurious fall and hip fracture up to 26 y before the diagnosis of Parkinson disease: nested case-control studies in a nationwide cohort. PLOS Med. 2016;13(2):e1001954.

57. Brandmeir NJ, Brandmeir CL, Kuzma K, McInerney J. A prospective evaluation of an outpatient assessment of postural instability to predict risk of falls in patients with Parkinson's disease presenting for deep brain stimulation. Mov Disord Clin Pract. 2016;3(2):151-5.

58. Paul SS, Sherrington C, Canning CG, Fung VS, Close JC, Lord SR. The relative contribution of physical and cognitive fall risk factors in people with Parkinson's disease: a large prospective cohort study. Neurorehabil Neural Repair. 2014;28(3):282-90.

59. Paul SS, Allen NE, Sherrington C, et al. Risk factors for frequent falls in people with Parkinson's disease. J Parkinsons Dis. 2014;4(4):699-703.

60. Camicioli R, Majumdar SR. Relationship between mild cognitive impairment and falls in older people with and without Parkinson's disease: 1-year prospective cohort study. Gait Posture. 2010;32(1):87-91.

61. Shaw FE. Prevention of falls in older people with dementia. J Neural Transm. 2007;114(10):1259-64.

62. Amar K, Stack E, Fitton C, Ashburn A, Roberts HC. Fall frequency, predicting falls and participating in falls research: similarities among people with Parkinson's disease with and without cognitive impairment. Parkinsonism Relat Disord. 2015;21(1):55-60.

63. Domingos JM, Godinho C, Dean J, et al. Cognitive impairment in fall-related studies in Parkinson's disease. J Parkinson's Dis. 2015;5(3):453-69.

64. Yogev G, Giladi N, Peretz C, Springer S, Simon ES, Hausdorff JM. Dual tasking, gait rhythmicity, and Parkinson's disease: which aspects of gait are attention demanding? Eur J Neurosci. 2005;22(5):1248-56.

65. Centi J, Freeman R, Gibbons $\mathrm{CH}$, Neargarder S, Canova AO, Cronin-Golomb A. Effects of orthostatic hypotension on cognition in Parkinson disease. Neurology. 2017;88(1):17-24.

66. Romagnolo A, Zibetti M, Merola A, et al. Cardiovascular autonomic neuropathy and falls in Parkinson disease: a prospective cohort study. J Neurol. 2019;266(1):85-91.

67. Anstey KJ, Von Sanden C, Luszcz MA. An 8-year prospective study of the relationship between cognitive performance and falling in very old adults. J Am Geriatr Soc. 2006;54(8):1169-76.

68. Muir SW, Gopaul K, Montero Odasso MM. The role of cognitive impairment in fall risk among older adults: a systematic review and meta-analysis. Age Ageing. 2012;41(3):299-308

69. van Dijk PT, Meulenberg OG, van de Sande HJ, Habbema JD. Falls in dementia patients. Gerontologist. 1993;33(2):200-4.

70. Martin KL, Blizzard L, Wood AG, et al. Cognitive function, gait, and gait variability in older people: a population-based study. J Gerontol Ser A. 2013;68(6):726-32.

71. Allan LM, Ballard CG, Burn DJ, Kenny RA. Prevalence and severity of gait disorders in Alzheimer's and non-Alzheimer's dementias. J Am Geriatr Soc. 2005;53(10):1681-7. 
72. McKeith IG, Perry RH, Fairbairn AF, Jabeen S, Perry EK. Operational criteria for senile dementia of Lewy body type (SDLT). Psychol Med. 1992;22(4):911-22.

73. Hanyu H, Sato T, Hirao K, Kanetaka H, Sakurai H, Iwamoto T. Differences in clinical course between dementia with Lewy bodies and Alzheimer's disease. Eur J Neurol. 2009;16(2):212-7.

74. Breitve MH, Chwiszczuk LJ, Hynninen MJ, et al. A systematic review of cognitive decline in dementia with Lewy bodies versus Alzheimer's disease. Alzheimer's Res Ther. 2014;6(5-8):53.

75. Mosimann UP, Mather G, Wesnes KA, O'Brien JT, Burn DJ, McKeith IG. Visual perception in Parkinson disease dementia and dementia with Lewy bodies. Neurology. 2004;63(11): 2091-6.

76. Kudo Y, Imamura T, Sato A, Endo N. Risk factors for falls in community-dwelling patients with Alzheimer's disease and dementia with Lewy bodies: walking with visuocognitive impairment may cause a fall. Dement Geriatr Cogn Disord. 2009;27(2):139-46.

77. Springer S, Giladi N, Peretz C, Yogev G, Simon ES, Hausdorff JM. Dual-tasking effects on gait variability: the role of aging, falls, and executive function. Mov Disord. 2006;21(7):950-7.

78. Wang HF, Yu JT, Tang SW, et al. Efficacy and safety of cholinesterase inhibitors and memantine in cognitive impairment in Parkinson's disease, Parkinson's disease dementia, and dementia with Lewy bodies: systematic review with meta-analysis and trial sequential analysis. J Neurol Neurosurg Psychiatry. 2015;86(2):135-43.

79. Kim DH, Brown RT, Ding EL, Kiel DP, Berry SD. Dementia medications and risk of falls, syncope, and related adverse events: meta-analysis of randomized controlled trials. J Am Geriatr Soc. 2011;59(6):1019-31.

80. Imamura $\mathrm{T}$, Hirono $\mathrm{N}$, Hashimoto $\mathrm{M}$, et al. Fall-related injuries in dementia with Lewy bodies (DLB) and Alzheimer's disease. Eur J Neurol. 2000;7(1):77-9.

81. Ballard CG, Shaw F, Lowery K, McKeith I, Kenny R. The prevalence, assessment and associations of falls in dementia with Lewy bodies and Alzheimer's disease. Dement Geriatr Cogn Disord. 1999;10(2):97-103.

82. Boeve BF, Dickson DW, Duda JE, et al. Arguing against the proposed definition changes of PD. Mov Disord. 2016;31(11):1619-22.

83. Aarsland D, Ballard C, McKeith I, Perry RH, Larsen JP. Comparison of extrapyramidal signs in dementia with Lewy bodies and Parkinson's disease. J Neuropsychiatry Clin Neurosci. 2001;13(3):374-9.

84. Del Ser T, McKeith I, Anand R, Cicin-Sain A, Ferrara R, Spiegel R. Dementia with Lewy bodies: findings from an international multicentre study. Int J Geriatr Psychiatry. 2000;15(11):1034-45.

85. Goldman JG, Goetz CG, Brandabur M, Sanfilippo M, Stebbins GT. Effects of dopaminergic medications on psychosis and motor function in dementia with Lewy bodies. Mov Disord. 2008;23(15):2248-50.

86. Burn DJ, Rowan EN, Minett T, et al. Extrapyramidal features in Parkinson's disease with and without dementia and dementia with Lewy bodies: a cross-sectional comparative study. Mov Disord. 2003;18(8):884-9.

87. Scharre DW, Chang SI, Nagaraja HN, et al. Paired studies comparing clinical profiles of Lewy body dementia with Alzheimer's and Parkinson's diseases. J Alzheimers Dis. 2016;54(3):995-1004.

88. Fritz NE, Kegelmeyer DA, Kloos AD, et al. Motor performance differentiates individuals with Lewy body dementia, Parkinson's and Alzheimer's disease. Gait Posture. 2016;50:1-7.

89. Factor SA. The clinical spectrum of freezing of gait in atypical parkinsonism. Mov Disord. 2008;23(Suppl 2):S431-8.

90. Palermo G, Frosini D, Corsi A, et al. Freezing of gait and dementia in parkinsonism: a retrospective case-control study. Brain Behav. 2019;9(6):e01247.

91. Kenny RA, Kalaria R, Ballard C. Neurocardiovascular instability in cognitive impairment and dementia. Ann N Y Acad Sci. 2002;977:183-95.
92. Thaisetthawatkul $\mathrm{P}$, Boeve BF, Benarroch EE, et al. Autonomic dysfunction in dementia with Lewy bodies. Neurology. 2004;62(10):1804-9.

93. Ungar A, Mussi C, Ceccofiglio A, et al. Etiology of syncope and unexplained falls in elderly adults with dementia: syncope and dementia (SYD) study. J Am Geriatr Soc. 2016;64(8): $1567-73$.

94. Andersson M, Hansson O, Minthon L, Ballard CG, Londos E. The period of hypotension following orthostatic challenge is prolonged in dementia with Lewy bodies. Int J Geriatr Psychiatry. 2008;23(2):192-8.

95. Stubendorff K, Aarsland D, Minthon L, Londos E. The impact of autonomic dysfunction on survival in patients with dementia with Lewy bodies and Parkinson's disease with dementia. PLoS One. 2012;7(10): e45451.

96. Tanaka R, Shimo Y, Yamashiro K, et al. Association between abnormal nocturnal blood pressure profile and dementia in Parkinson's disease. Parkinsonism Relat Disord. 2018;46:24-9.

97. Robertson AD, Messner MA, Shirzadi Z, et al. Orthostatic hypotension, cerebral hypoperfusion, and visuospatial deficits in Lewy body disorders. Parkinsonism Relat Disord. 2016;22:80-6.

98. Gill SS, Anderson GM, Fischer HD, et al. Syncope and its consequences in patients with dementia receiving cholinesterase inhibitors: a population-based cohort study. Arch Intern Med. 2009;169(9):867-73.

99. Donnelly K, Bracchi R, Hewitt J, Routledge PA, Carter B. Benzodiazepines, Z-drugs and the risk of hip fracture: a systematic review and meta-analysis. PLoS One. 2017;12(4):e0174730.

100. Noack C, Schroeder C, Heusser K, Lipp A. Cardiovascular effects of levodopa in Parkinson's disease. Parkinsonism Relat Disord. 2014;20(8):815-8.

101. Watanabe H, Saito Y, Terao S, et al. Progression and prognosis in multiple system atrophy: an analysis of 230 Japanese patients. Brain. 2002;125(Pt 5):1070-83.

102. Kollensperger M, Geser F, Ndayisaba JP, et al. Presentation, diagnosis, and management of multiple system atrophy in Europe: final analysis of the European multiple system atrophy registry. Mov Disord. 2010;25(15):2604-12.

103. Stankovic I, Krismer F, Jesic A, et al. Cognitive impairment in multiple system atrophy: a position statement by the Neuropsychology Task Force of the MDS Multiple System Atrophy (MODIMSA) study group. Mov Disord. 2014;29(7):857-67.

104. Rascol O, Brooks DJ, Korczyn AD, De Deyn PP, Clarke CE, Lang AE. A five-year study of the incidence of dyskinesia in patients with early Parkinson's disease who were treated with ropinirole or levodopa. N Engl J Med. 2000;342(20): 1484-91.

105. Parkinson Study G. Dopamine transporter brain imaging to assess the effects of pramipexole vs levodopa on Parkinson disease progression. JAMA. 2002;287(13):1653-61.

106. Giladi N, McDermott MP, Fahn S, et al. Freezing of gait in PD: prospective assessment in the DATATOP cohort. Neurology. 2001;56(12):1712-21.

107. Shoulson I. DATATOP: a decade of neuroprotective inquiry. Parkinson Study Group. Deprenyl and tocopherol antioxidative therapy of parkinsonism. Ann Neurol. 1998;44(3 Suppl 1): S160-6.

108. Rascol O, Brooks DJ, Melamed E, et al. Rasagiline as an adjunct to levodopa in patients with Parkinson's disease and motor fluctuations (LARGO, Lasting effect in Adjunct therapy with Rasagiline Given Once daily, study): a randomised, double-blind, parallelgroup trial. Lancet. 2005;365(9463):947-54.

109. Kondo T. Drug intervention for freezing of gait resistant to dopaminergic therapy: a pilot study. Parkinsonism Relat Disord. 2006;12(Suppl 2):S63-6.

110. Kim YE, Yun JY, Yang HJ, et al. Intravenous amantadine for freezing of gait resistant to dopaminergic therapy: a randomized, double-blind, placebo-controlled, cross-over clinical trial. PLoS One. 2012;7(11):e48890.

111. Lee JY, Oh S, Kim JM, et al. Intravenous amantadine on freezing of gait in Parkinson's disease: a randomized controlled trial. J Neurol. 2013;260(12):3030-8. 
112. Malkani R, Zadikoff C, Melen O, Videnovic A, Borushko E, Simuni T. Amantadine for freezing of gait in patients with Parkinson disease. Clin Neuropharmacol. 2012;35(6):266-8.

113. Hauser RA, Heritier S, Rowse GJ, Hewitt LA, Isaacson SH. Droxidopa and reduced falls in a trial of Parkinson disease patients with neurogenic orthostatic hypotension. Clin Neuropharmacol. 2016;39(5):220-6.

114. Fukada K, Endo T, Yokoe M, Hamasaki T, Hazama T, Sakoda S. L-threo-3,4-dihydroxyphenylserine (L-DOPS) co-administered with entacapone improves freezing of gait in Parkinson's disease. Med Hypotheses. 2013;80(2):209-12.

115. Chung KA, Lobb BM, Nutt JG, Horak FB. Effects of a central cholinesterase inhibitor on reducing falls in Parkinson disease. Neurology. 2010;75(14):1263-9.

116. Henderson EJ, Lord SR, Brodie MA, et al. Rivastigmine for gait stability in patients with Parkinson's disease (ReSPonD): a randomised, double-blind, placebo-controlled, phase 2 trial. Lancet Neurol. 2016;15(3):249-58.

117. Crispo JA, Willis AW, Thibault DP, et al. Associations between anticholinergic burden and adverse health outcomes in Parkinson disease. PLoS One. 2016;11(3):e0150621.

118. Martinez-Ramirez D, Giugni JC, Almeida L, et al. Association between antidepressants and falls in Parkinson's disease. J Neurol. 2016;263(1):76-82.

119. Auriel E, Hausdorff JM, Herman T, Simon ES, Giladi N. Effects of methylphenidate on cognitive function and gait in patients with Parkinson's disease: a pilot study. Clin Neuropharmacol. 2006;29(1):15-7.

120. Pollak L, Dobronevsky Y, Prohorov T, Bahunker S, Rabey JM. Low dose methylphenidate improves freezing in advanced Parkinson's disease during off-state. J Neural Transm Suppl. 2007(72):145-8.

121. Espay AJ, Dwivedi AK, Payne M, et al. Methylphenidate for gait impairment in Parkinson disease: a randomized clinical trial. Neurology. 2011;76(14):1256-62.

122. Hamani C, Richter E, Schwalb JM, Lozano AM. Bilateral subthalamic nucleus stimulation for Parkinson's disease: a systematic review of the clinical literature. Neurosurgery. 2008;62(Suppl 2): 1313-24.

123. Schlenstedt C, Shalash A, Muthuraman M, Falk D, Witt K, Deuschl G. Effect of high-frequency subthalamic neurostimulation on gait and freezing of gait in Parkinson's disease: a systematic review and meta-analysis. Eur $\mathbf{J}$ Neurol. 2017;24(1):18-26.

124. Ferraye MU, Debu B, Fraix V, et al. Effects of pedunculopontine nucleus area stimulation on gait disorders in Parkinson's disease. Brain. 2010;133(Pt 1):205-14.

125. Moro E, Hamani C, Poon YY, et al. Unilateral pedunculopontine stimulation improves falls in Parkinson's disease. Brain. 2010;133(Pt 1):215-24.

126. Thevathasan W, Pogosyan A, Hyam JA, et al. Alpha oscillations in the pedunculopontine nucleus correlate with gait performance in parkinsonism. Brain. 2012;135(Pt 1):148-60.

127. Weiss D, Walach M, Meisner C, et al. Nigral stimulation for resistant axial motor impairment in Parkinson's disease? A randomized controlled trial. Brain. 2013;136(Pt 7):2098-2108.

128. Verghese J, Mahoney J, Ambrose AF, Wang C, Holtzer R. Effect of cognitive remediation on gait in sedentary seniors. J Gerontol A Biol Sci Med Sci. 2010;65(12):1338-43.

129. Silsupadol P, Shumway-Cook A, Lugade V, et al. Effects of singletask versus dual-task training on balance performance in older adults: a double-blind, randomized controlled trial. Arch Phys Med Rehabil. 2009;90(3):381-7.

130. Mirelman A, Maidan I, Herman T, Deutsch JE, Giladi N, Hausdorff JM. Virtual reality for gait training: can it induce motor learning to enhance complex walking and reduce fall risk in patients with Parkinson's disease? J Gerontol A Biol Sci Med Sci. 2011;66(2):234-40.

131. You JH, Shetty A, Jones T, Shields K, Belay Y, Brown D. Effects of dual-task cognitive-gait intervention on memory and gait dynamics in older adults with a history of falls: a preliminary investigation. NeuroRehabilitation. 2009;24(2):193-8.
132. Li F, Harmer P, Fitzgerald K, et al. Tai chi and postural stability in patients with Parkinson's disease. $N$ Engl $J$ Med. 2012;366(6):511-9.

133. Morris ME, Menz HB, McGinley JL, et al. A randomized controlled trial to reduce falls in people with Parkinson's disease. Neurorehabil Neural Repair. 2015;29(8):777-85.

134. Sparrow D, DeAngelis TR, Hendron K, Thomas CA, SaintHilaire M, Ellis T. Highly challenging balance program reduces fall rate in Parkinson disease. J Neurol Phys Ther. 2016;40(1):24-30.

135. Wong-Yu IS, Mak MK. Task- and context-specific balance training program enhances dynamic balance and functional performance in Parkinsonian nonfallers: a randomized controlled trial with six-month follow-up. Arch Phys Med Rehabil. 2015;96(12):2103-11

136. Shen X, Mak MK. Technology-assisted balance and gait training reduces falls in patients with Parkinson's disease: a randomized controlled trial with 12-month follow-up. Neurorehabil Neural Repair. 2015;29(2):103-11.

137. Morris ME, Martin C, McGinley JL, et al. Protocol for a homebased integrated physical therapy program to reduce falls and improve mobility in people with Parkinson's disease. BMC Neurol. 2012;12:54.

138. Frazzitta G, Maestri R, Uccellini D, Bertotti G, Abelli P. Rehabilitation treatment of gait in patients with Parkinson's disease with freezing: a comparison between two physical therapy protocols using visual and auditory cues with or without treadmill training. Mov Disord. 2009;24(8):1139-43.

139. McNeely ME, Mai MM, Duncan RP, Earhart GM. Differential effects of Tango versus dance for PD in Parkinson disease. Front Aging Neurosci. 2015;7:239.

140. Dixon L, Duncan D, Johnson P, et al. Occupational therapy for patients with Parkinson's disease. Cochrane Database Syst Rev. 2007;(3):CD002813.

141. Hale WA, Delaney MJ, Cable T. Accuracy of patient recall and chart documentation of falls. J Am Board Fam Pract. 1993;6(3):239-42.

142. Ashburn A, Stack E, Ballinger C, Fazakarley L, Fitton C. The circumstances of falls among people with Parkinson's disease and the use of Falls Diaries to facilitate reporting. Disabil Rehabil. 2008;30(16):1205-12.

143. Hunter H, Rochester L, Morris R, Lord S. Longitudinal falls data in Parkinson's disease: feasibility of fall diaries and effect of attrition. Disabil Rehabil. 2018;40(19):2236-41.

144. Ross A, Yarnall AJ, Rochester L, Lord S. A novel approach to falls classification in Parkinson's disease: development of the Fall-Related Activity Classification (FRAC). Physiotherapy. 2017;103(4):459-64.

145. Klawans HL. Individual manifestations of Parkinson's disease after ten or more years of levodopa. Mov Disord. 1986;1(3):187-92.

146. Agid Y, Graybiel AM, Ruberg M, et al. The efficacy of levodopa treatment declines in the course of Parkinson's disease: do nondopaminergic lesions play a role? Adv Neurol. 1990;53:83-100.

147. Curtze C, Nutt JG, Carlson-Kuhta P, Mancini M, Horak FB. Levodopa is a double-edged sword for balance and gait in people with Parkinson's disease. Mov Disord. 2015;30(10):1361-70

148. Bejjani BP, Gervais D, Arnulf I, et al. Axial parkinsonian symptoms can be improved: the role of levodopa and bilateral subthalamic stimulation. J Neurol Neurosurg Psychiatry. 2000;68(5):595-600

149. Bonnet AM, Loria Y, Saint-Hilaire MH, Lhermitte F, Agid Y. Does long-term aggravation of Parkinson's disease result from nondopaminergic lesions? Neurology. 1987;37(9):1539-42.

150. Agid Y. Parkinson's disease: pathophysiology. Lancet. 1991;337(8753):1321-4

151. Smulders K, Esselink RA, Cools R, Bloem BR. Trait impulsivity is associated with the risk of falls in Parkinson's disease. PLoS One. 2014;9(3):e91190.

152. Holloway RG, Shoulson I, Fahn S, et al. Pramipexole vs levodopa as initial treatment for Parkinson disease: a 4-year randomized controlled trial. Arch Neurol. 2004;61(7):1044-53. 
153. Fernandez HH, Wu CK, Ott BR. Pharmacotherapy of dementia with Lewy bodies. Expert Opin Pharmacother. 2003;4(11):2027-37.

154. Benabid AL, Pollak P, Louveau A, Henry S, de Rougemont J. Combined (thalamotomy and stimulation) stereotactic surgery of the VIM thalamic nucleus for bilateral Parkinson disease. Appl Neurophysiol. 1987;50(1-6):344-6.

155. Fasano A, Romito LM, Daniele A, et al. Motor and cognitive outcome in patients with Parkinson's disease 8 years after subthalamic implants. Brain. 2010;133(9):2664-76.

156. Rizzone MG, Fasano A, Daniele A, et al. Long-term outcome of subthalamic nucleus DBS in Parkinson's disease: from the advanced phase towards the late stage of the disease? Parkinsonism Relat Disord. 2014;20(4):376-81.

157. Ferraye MU, Deba B, Pollak P. Deep brain stimulation effect on freezing of gait. Mov Disord. 2008;23:S489-94.

158. Castrioto A, Lozano AM, Poon YY, Lang AE, Fallis M, Moro E. Ten-year outcome of subthalamic stimulation in Parkinson disease: a blinded evaluation. Arch Neurol. 2011;68(12): 1550-6.

159. Cossu G, Pau M. Subthalamic nucleus stimulation and gait in Parkinson's disease: a not always fruitful relationship. Gait Posture. 2017;52:205-10.

160. Guzzi G, Della Torre A, Chirchiglia D, Volpentesta G, Lavano A. Critical reappraisal of DBS targeting for movement disorders. J Neurosurg Sci. 2016;60(2):181-8.

161. Collomb-Clerc A, Welter ML. Effects of deep brain stimulation on balance and gait in patients with Parkinson's disease: a systematic neurophysiological review. Neurophysiol Clin. 2015;45(4-5):371-88.

162. Okun MS, Gallo BV, Mandybur G, et al. Subthalamic deep brain stimulation with a constant-current device in Parkinson's disease: an open-label randomised controlled trial. Lancet Neurol. 2012;11(2):140-9.

163. Rodriguez-Oroz MC, Obeso JA, Lang AE, et al. Bilateral deep brain stimulation in Parkinson's disease: a multicentre study with 4 years follow-up. Brain. 2005;128(Pt 10):2240-9.

164. Karachi C, Cormier-Dequaire F, Grabli D, et al. Clinical and anatomical predictors for freezing of gait and falls after subthalamic deep brain stimulation in Parkinson's disease patients. Parkinsonism Relat Disord. 2019;62:91-7.

165. Follett KA, Weaver FM, Stern M, et al. Pallidal versus subthalamic deep-brain stimulation for Parkinson's disease. N Engl J Med. 2010;362(22):2077-91.

166. van Nuenen BF, Esselink RA, Munneke M, Speelman JD, van Laar T, Bloem BR. Postoperative gait deterioration after bilateral subthalamic nucleus stimulation in Parkinson's disease. Mov Disord. 2008;23(16):2404-6.

167. Ferraye MU, Debu B, Fraix V, et al. Effects of subthalamic nucleus stimulation and levodopa on freezing of gait in Parkinson disease. Neurology. 2008;70(16 Pt 2):1431-7.

168. McNeely ME, Earhart GM. Medication and subthalamic nucleus deep brain stimulation similarly improve balance and complex gait in Parkinson disease. Parkinsonism Relat Disord. 2013;19(1): 86-91.

169. Crenna P, Carpinella I, Rabuffetti M, et al. Impact of subthalamic nucleus stimulation on the initiation of gait in Parkinson's disease. Exp Brain Res. 2006;172(4):519-32.

170. Stolze H, Klebe S, Poepping M, et al. Effects of bilateral subthalamic nucleus stimulation on parkinsonian gait. Neurology. 2001;57(1):144-6.

171. Xu F, Ma W, Huang Y, Qiu Z, Sun L. Deep brain stimulation of pallidal versus subthalamic for patients with Parkinson's disease: a meta-analysis of controlled clinical trials. Neuropsychiatr Dis Treat. 2016;12:1435-44.

172. Tattersall TL, Stratton PG, Coyne TJ, et al. Imagined gait modulates neuronal network dynamics in the human pedunculopontine nucleus. Nat Neurosci. 2014;17(3):449-54.

173. Lee MS, Rinne JO, Marsden CD. The pedunculopontine nucleus: its role in the genesis of movement disorders. Yonsei Med J. 2000;41(2):167-84.

174. Thevathasan W, Moro E. What is the therapeutic mechanism of pedunculopontine nucleus stimulation in Parkinson's disease? Neurobiol Dis. 2019;128.
175. Mazzone P, Lozano A, Stanzione P, et al. Implantation of human pedunculopontine nucleus: a safe and clinically relevant target in Parkinson's disease. Neuroreport. 2005;16(17):1877-81.

176. Stefani A, Lozano AM, Peppe A, et al. Bilateral deep brain stimulation of the pedunculopontine and subthalamic nuclei in severe Parkinson's disease. Brain. 2007;130(Pt 6):1596-607.

177. Strafella AP, Lozano AM, Ballanger B, Poon YY, Lang AE, Moro E. rCBF changes associated with PPN stimulation in a patient with Parkinson's disease: a PET study. Mov Disord. 2008;23(7):1051-4.

178. Thevathasan W, Silburn PA, Brooker H, et al. The impact of lowfrequency stimulation of the pedunculopontine nucleus region on reaction time in parkinsonism. J Neurol Neurosurg Psychiatry. 2010;81(10):1099-104.

179. Khan S, Mooney L, Plaha P, et al. Outcomes from stimulation of the caudal zona incerta and pedunculopontine nucleus in patients with Parkinson's disease. Br J Neurosurg. 2011;25(2):273-80.

180. Nosko D, Ferraye MU, Fraix V, et al. Low-frequency versus highfrequency stimulation of the pedunculopontine nucleus area in Parkinson's disease: a randomised controlled trial. J Neurol Neurosurg Psychiatry. 2015;86(6):674-9.

181. Boisgontier MP, Cheval B, Chalavi S, et al. Individual differences in brainstem and basal ganglia structure predict postural control and balance loss in young and older adults. Neurobiol Aging. 2017;50:47-59.

182. Castrioto A, Moro E. New targets for deep brain stimulation treatment of Parkinson's disease. Expert Rev Neurother. 2013;13(12):1319-28.

183. Udupa K, Chen R. The mechanisms of action of deep brain stimulation and ideas for the future development. Prog Neurobiol. 2015;133:27-49.

184. Takakusaki K, Chiba R, Nozu T, Okumura T. Brainstem control of locomotion and muscle tone with special reference to the role of the mesopontine tegmentum and medullary reticulospinal systems. J Neural Transm (Vienna). 2016;123(7):695-729.

185. Brosius SN, Gonzalez CL, Shuresh J, Walker HC. Reversible improvement in severe freezing of gait from Parkinson's disease with unilateral interleaved subthalamic brain stimulation. Parkinsonism Relat Disord. 2015;21(12):1469-70.

186. Chastan N, Westby GW, Yelnik J, et al. Effects of nigral stimulation on locomotion and postural stability in patients with Parkinson's disease. Brain. 2009;132(Pt 1):172-84.

187. Weiss D, Klotz R, Govindan RB, et al. Subthalamic stimulation modulates cortical motor network activity and synchronization in Parkinson's disease. Brain. 2015;138(Pt 3):679-93.

188. Gilat M, Ligia Silva de Lima A, Bloem BR, Shine JM, Nonnekes J, Lewis SJG. Freezing of gait: promising avenues for future treatment. Parkinsonism Relat Disord. 2018;52:7-16.

189. Samotus O, Parrent A, Jog M. Spinal cord stimulation therapy for gait dysfunction in advanced Parkinson's disease patients. Mov Disord. 2018;33(5):783-92.

190. Pinto de Souza C, Hamani C, Oliveira Souza C, et al. Spinal cord stimulation improves gait in patients with Parkinson's disease previously treated with deep brain stimulation. Mov Disord. 2017;32(2):278-82.

191. Sanchez-Ferro A, Benito-Leon J, Gomez-Esteban JC. The management of orthostatic hypotension in Parkinson's disease. Front Neurol. 2013;4:64.

192. Fanciulli A, Wenning GK. Multiple-system atrophy. N Engl J Med. 2015;372(3):249-63.

193. Palma JA, Kaufmann H. Epidemiology, diagnosis, and management of neurogenic orthostatic hypotension. Mov Disord Clin Pract. 2017;4(3):298-308.

194. Poletti M, Bonuccelli U. Acute and chronic cognitive effects of levodopa and dopamine agonists on patients with Parkinson's disease: a review. Ther Adv Psychopharmacol. 2013;3(2):101-13.

195. Fischer C, Bozanovic R, Atkins JH, Rourke SB. Treatment of delusions in dementia with Lewy bodies - response to pharmacotherapy. Dement Geriatr Cogn Disord. 2007;23(5):307-11.

196. Carlson DL, Fleming KC, Smith GE, Evans JM. Management of dementia-related behavioral disturbances: a nonpharmacologic approach. Mayo Clin Proc. 1995;70(11):1108-15. 
197. Teri L, Logsdon RG, McCurry SM. Nonpharmacologic treatment of behavioral disturbance in dementia. Med Clin North Am. 2002;86(3):641-56, viii.

198. Montero-Odasso M, Verghese J, Beauchet O, Hausdorff JM. Gait and cognition: a complementary approach to understanding brain function and the risk of falling. $\mathrm{J}$ Am Geriatr Soc. 2012;60(11):2127-36.

199. Samuel W, Caligiuri M, Galasko D, et al. Better cognitive and psychopathologic response to donepezil in patients prospectively diagnosed as dementia with Lewy bodies: a preliminary study. Int J Geriatr Psychiatry. 2000;15(9):794-802.

200. Emre M, Tsolaki M, Bonuccelli U, et al. Memantine for patients with Parkinson's disease dementia or dementia with Lewy bodies: a randomised, double-blind, placebo-controlled trial. Lancet Neurol. 2010;9(10):969-77.

201. Aarsland D, Ballard C, Walker Z, et al. Memantine in patients with Parkinson's disease dementia or dementia with Lewy bodies: a double-blind, placebo-controlled, multicentre trial. Lancet Neurol. 2009;8(7):613-8.

202. Campos C, Rocha NB, Lattari E, Paes F, Nardi AE, Machado S. Exercise-induced neuroprotective effects on neurodegenerative diseases: the key role of trophic factors. Expert Rev Neurother. 2016;16(6):723-34.

203. da Silva PG, Domingues DD, de Carvalho LA, Allodi S, Correa CL. Neurotrophic factors in Parkinson's disease are regulated by exercise: evidence-based practice. J Neurol Sci. 2016;363:5-15.

204. Goodwin VA, Abbott RA, Whear R, et al. Multiple component interventions for preventing falls and fall-related injuries among older people: systematic review and meta-analysis. BMC Geriatr. 2014; $14: 15$

205. Tricco AC, Cogo E, Holroyd-Leduc J, et al. Efficacy of falls prevention interventions: protocol for a systematic review and network meta-analysis. Syst Rev. 2013;2:38.

206. Chang JT, Morton SC, Rubenstein LZ, et al. Interventions for the prevention of falls in older adults: systematic review and metaanalysis of randomised clinical trials. BMJ. 2004;328(7441):680.

207. Sherrington C, Michaleff ZA, Fairhall N, et al. Exercise to prevent falls in older adults: an updated systematic review and metaanalysis. Br J Sports Med. 2017;51(24):1750-8.

208. Rimland JM, Abraha I, Dell'Aquila G, et al. Effectiveness of nonpharmacological interventions to prevent falls in older people: a systematic overview. The SENATOR Project ONTOP series. PLoS One. 2016;11(8):e0161579.

210. Suteerawattananon M, Morris GS, Etnyre BR, Jankovic J, Protas EJ. Effects of visual and auditory cues on gait in individuals with Parkinson's disease. J Neurol Sci. 2004;219(1-2):63-9.

210. Ledger S, Galvin R, Lynch D, Stokes EK. A randomised controlled trial evaluating the effect of an individual auditory cueing device on freezing and gait speed in people with Parkinson's disease. BMC Neurol. 2008;8:46.

211. Arias P, Cudeiro J. Effect of rhythmic auditory stimulation on gait in Parkinsonian patients with and without freezing of gait. PLoS One. 2010;5(3):e9675

212. Satoh M, Kuzuhara S. Training in mental singing while walking improves gait disturbance in Parkinson's disease patients. Eur Neurol. 2008;60(5):237-43.

213. Morris ME, Taylor NF, Watts JJ, et al. A home program of strength training, movement strategy training and education did not prevent falls in people with Parkinson's disease: a randomised trial. J Physiother. 2017;63(2):94-100.

214. McKay JL, Ting LH, Hackney ME. Balance, body motion, and muscle activity after high-volume short-term dance-based rehabilitation in persons with Parkinson disease: a pilot study. J Neurol Phys Ther. 2016;40(4):257-68.

215. Duncan RP, Earhart GM. Are the effects of community-based dance on Parkinson disease severity, balance, and functional mobility reduced with time? A 2-year prospective pilot study. J Altern Complement Med. 2014;20(10):757-63.

216. Gregson CL, Dennison EM, Compston JE, et al. Disease-specific perception of fracture risk and incident fracture rates: GLOW cohort study. Osteoporos Int. 2014;25(1):85-95.
217. Johnell O, Sernbo I. Health and social status in patients with hip fractures and controls. Age Ageing. 1986;15(5):285-91.

218. Metta V, Sanchez TC, Padmakumar C. Osteoporosis: a hidden nonmotor face of Parkinson's disease. Int Rev Neurobiol. 2017;134:877-90.

219. Binks S, Dobson R. Risk factors, epidemiology and treatment strategies for metabolic bone disease in patients with neurological disease. Curr Osteoporos Rep. 2016;14(5):199-210.

220. Cumming RG. Intervention strategies and risk-factor modification for falls prevention. A review of recent intervention studies. Clin Geriatr Med. 2002;18(2):175-89.

221. Neyens JC, van Haastregt JC, Dijcks BP, et al. Effectiveness and implementation aspects of interventions for preventing falls in elderly people in long-term care facilities: a systematic review of RCTs. J Am Med Dir Assoc. 2011;12(6):410-25.

222. Gillespie L. Preventing falls in elderly people. BMJ. 2004;328(7441):653-4.

223. Gillespie LD, Gillespie WJ, Robertson MC, Lamb SE, Cumming $\mathrm{RG}$, Rowe $\mathrm{BH}$. Interventions for preventing falls in elderly people. Cochrane Database Syst Rev. 2003;(4):CD000340.

224. Hill-Westmoreland EE, Gruber-Baldini AL. Falls documentation in nursing homes: agreement between the minimum data set and chart abstractions of medical and nursing documentation. J Am Geriatr Soc. 2005;53(2):268-73.

225. Nowacka B, Lubinski W, Honczarenko K, Potemkowski A, Safranow K. Ophthalmological features of Parkinson disease. Med Sci Monit. 2014;20:2243-9.

226. Lai SW, Lin CL, Liao KF, Chang-Ou KC. Increased risk of Parkinson's disease in cataract patients: a population-based cohort study. Parkinsonism Relat Disord. 2015;21(1):68-71.

227. Harwood RH, Foss AJ, Osborn F, Gregson RM, Zaman A, Masud T. Falls and health status in elderly women following first eye cataract surgery: a randomised controlled trial. $\mathrm{Br} \mathrm{J}$ Ophthalmol. 2005;89(1):53-9.

228. Kenny RA, Richardson DA, Steen N, Bexton RS, Shaw FE, Bond J. Carotid sinus syndrome: a modifiable risk factor for nonaccidental falls in older adults (SAFE PACE). J Am Coll Cardiol. 2001;38(5):1491-6.

229. Parry MJ, Watt-Watson J, Hodnett E, Tranmer J, Dennis CL, Brooks D. Cardiac Home Education and Support Trial (CHEST): a pilot study. Can J Cardiol. 2009;25(12):e393-8.

230. Zhang L, Cao B, Zou Y, et al. Causes of death in Chinese patients with multiple system atrophy. Aging Dis. 2018;9(1):102-8.

231. Papapetropoulos S, Tuchman A, Laufer D, Papatsoris AG, Papapetropoulos N, Mash DC. Causes of death in multiple system atrophy. J Neurol Neurosurg Psychiatry. 2007;78(3): 327-9.

232. Mirelman A, Giladi N, Hausdorff JM. Body-fixed sensors for Parkinson disease. JAMA. 2015;314(9):873-4.

233. Morris R, Hickey A, Del Din S, Godfrey A, Lord S, Rochester L. A model of free-living gait: a factor analysis in Parkinson's disease. Gait Posture. 2017:52:68-71.

234. Weiss A, Herman T, Giladi N, Hausdorff JM. Objective assessment of fall risk in Parkinson's disease using a body-fixed sensor worn for 3 days. PLoS One. 2014;9(5):e96675.

235. Fasano A, Canning CG, Hausdorff JM, Lord S, Rochester L. Falls in Parkinson's disease: a complex and evolving picture. Mov Disord. 2017;32(11):1524-36.

236. Buchman AS, Leurgans SE, Weiss A, et al. Associations between quantitative mobility measures derived from components of conventional mobility testing and Parkinsonian gait in older adults. PLoS One. 2014;9(1):e86262.

237. Austin D, Hayes TL, Kaye J, Mattek N, Pavel M. Unobtrusive monitoring of the longitudinal evolution of in-home gait velocity data with applications to elder care. Conf Proc IEEE Eng Med Biol Soc. 2011;2011:6495-8.

238. Kaye J, Mattek N, Dodge H, et al. One walk a year to 1000 within a year: continuous in-home unobtrusive gait assessment of older adults. Gait Posture. 2012;35(2):197-202.

239. Mirelman A, Rochester L, Maidan I, et al. Addition of a nonimmersive virtual reality component to treadmill training to reduce fall risk in older adults (V-TIME): a randomised controlled trial. Lancet. 2016;388(10050):1170-82. 
240. Wassermann EM, Lisanby SH. Therapeutic application of repetitive transcranial magnetic stimulation: a review. Clin Neurophysiol. 2001;112(8):1367-77.

241. Chou YH, Hickey PT, Sundman M, Song AW, Chen NK. Effects of repetitive transcranial magnetic stimulation on motor symptoms in Parkinson disease: a systematic review and meta-analysis. JAMA Neurol. 2015;72(4):432-40.

242. Dagan M, Herman T, Mirelman A, Giladi N, Hausdorff JM. The role of the prefrontal cortex in freezing of gait in Parkinson's disease: insights from a deep repetitive transcranial magnetic stimulation exploratory study. Exp Brain Res. 2017;235(8): 2463-72.

243. Tard C, Devanne H, Defebvre L, Delval A. Single session intermittent theta-burst stimulation on the left premotor cortex does not alleviate freezing of gait in Parkinson's disease. Neurosci Lett. 2016.
244. Chang WH, Kim MS, Park E, et al. Effect of dual-mode and dual-site noninvasive brain stimulation on freezing of gait in patients with Parkinson disease. Arch Phys Med Rehabil. 2017;98(7):1283-90.

245. Rektorova I, Sedlackova S, Telecka S, Hlubocky A, Rektor I. Repetitive transcranial stimulation for freezing of gait in Parkinson's disease. Mov Disord. 2007;22(10):1518-9.

246. Kim MS, Chang WH, Cho JW, et al. Efficacy of cumulative highfrequency rTMS on freezing of gait in Parkinson's disease. Restor Neurol Neurosci. 2015;33(4):521-30.

247. Valentino F, Cosentino G, Brighina F, et al. Transcranial direct current stimulation for treatment of freezing of gait: a cross-over study. Mov Disord. 2014;29(8):1064-9.

248. Dagan M, Herman T, Harrison R, et al. Multitarget transcranial direct current stimulation for freezing of gait in Parkinson's disease. Mov Disord. 2018;33(4):642-6. 